\title{
Archaeal and Bacterial Diversity and Distribution Patterns in Mediterranean-Climate Vernal Pools of Mexico and the Western USA
}

\author{
Jorge A. Mandussí Montiel-Molina ${ }^{1,2,3}$ (i) $\cdot$ Jason P. Sexton ${ }^{1}$ (D) A. Carolin Frank ${ }^{1}$ (D) - J. Michael Beman ${ }^{1}$ (i)
}

Received: 7 June 2021 / Accepted: 7 December 2021 / Published online: 31 December 2021

(c) The Author(s) 2021

\begin{abstract}
Biogeographic patterns in microorganisms are poorly understood, despite the importance of microbial communities for a range of ecosystem processes. Our knowledge of microbial ecology and biogeography is particularly deficient in rare and threatened ecosystems. We tested for three ecological patterns in microbial community composition within ephemeral wetlands_-vernal pools—located across Baja California (Mexico) and California (USA): (1) habitat filtering; (2) a latitudinal diversity gradient; and (3) distance decay in community composition. Paired water and soil samples were collected along a latitudinal transect of vernal pools, and bacterial and archaeal communities were characterized using 16S rDNA sequencing. We identified two main microbial communities, with one community present in the soil matrix that included archaeal and bacterial soil taxa, and another community present in the overlying water that was dominated by common freshwater bacterial taxa. Aquatic microbial communities were more diverse in the north, and displayed a significant but inverted latitudinal diversity pattern. Aquatic communities also exhibited a significant distance-decay pattern, with geographic proximity, and precipitation explaining part of the community variation. Collectively these results indicate greater sensitivity to spatial and environmental variation in vernal pool aquatic microbial communities than in soil microbial communities. We conclude that vernal pool aquatic microbial communities can display distribution patterns similar to those exhibited by larger organisms, but differ in some key aspects, such as the latitudinal gradient in diversity.
\end{abstract}

Keywords Ephemeral wetlands $\cdot$ Archaea $\cdot$ Bacteria $\cdot$ Inverse latitudinal gradient $\cdot$ Distance-decay $\cdot$ Environmental filtering

\section{Introduction}

Microorganisms play multiple ecological roles in terrestrial and aquatic ecosystems, from acting as symbionts and parasites to regulating biogeochemical cycles. Quantifying how microbial communities assemble and how microbial taxa are distributed across ecosystems is therefore important to our understanding of ecological equilibrium. As such, a central question in microbial ecology is the degree to which

Jorge A. Mandussí Montiel-Molina

jmontielmolina@ucmerced.edu

1 Environmental Systems, Department of Life and Environmental Science, University of California Merced, North Lake Road 5200, Merced, CA 95343, USA

2 Nativos de Las Californias A.C, Cuarto Balcón 15901, Balcón Las Huertas, Tijuana, Baja California 22116, México

3 Jardín Botánico de San Quintín A.C, Gral. Esteban Cantú 200, Nuevo Baja California, San Quintín-Lazaro Cárdenas, Baja California 22930, México microbes follow ecological patterns displayed by "macroorganisms" [9, 16, 17, 26, 35, 50]. Traditionally, microorganisms were thought to be widely distributed in all ecosystems due to their small size and high dispersal rates, with the environment responsible for "selecting" microorganisms according to their metabolic attributes $[1,44]$. Niche theory predicts community composition as a result of environmental filtering, and irrespective of geographic proximity [42] —for example, salinity, temperature variation, oxygen limitation, and other particular conditions can strongly influence microbial community assembly in natural habitats [22, 39, 45, 49]. However, it is equally clear that a combination of historical events and contemporary factors are important in determining diversity and community composition, and that microbial communities can display broad biogeographic patterns $[12,26,50]$. Ultimately, microbial communities distributed within and across different ecosystems may be shaped by different assembly processes to differing degrees, providing insight into microbial community assembly in comparison to larger organisms. 
Vernal pools are ideal systems in which to examine microbial community assembly given the inherent attributes of these ecosystems. Reflecting the climatic extremes typical of Mediterranean-climate ecosystems (moist and cold winters followed by hot and dry summers), vernal pools can form where water collects in shallow depressions with a high clay content and a deeper cemented layer (which prevents water percolation to the subsoil). Defined as temporary wetlands, and characterized by consecutive aquatic and terrestrial phases, vernal pools display seasonal transitions from completely flooded to totally desiccated soils [48]. During winters with sufficient precipitation, vernal pools fill with rainwater, creating water "islands" embedded in a surrounding terrestrial ecosystem. Vernal pools then progressively retract and eventually dry out in warmer months as evapotranspiration exceeds precipitation. Vernal pools therefore encompass both aquatic as well as soil habitats-which both vary strongly over the year, and may interact in various ways (e.g., via species that transition between the different environments, or via fluxes of carbon and nutrients). How microorganisms colonize these ecosystems, and tolerate the variations within them, directly addresses the roles of geography versus environment in affecting community assembly.

In soil, seasonal fluctuations from inundation to aridity likely create strong environmental variations. Under one extreme, saturated soils often reach anoxic conditions that may affect the distribution of microorganisms [7]. On the other extreme, dry and hot conditions during Mediterranean-type summers may require adaptations-for example, desiccation-adapted microalgae may persist dormant on dry stream beds until water flow resumes [43]. During the rainy season, inundated vernal pools resemble permanent aquatic ecosystems, however, the strong seasonality of Mediterranean-climate vernal pools shares attributes with other ephemeral aquatic ecosystems like seasonally flooded deltas, wetlands (pitlands), or floodplains [27, 37]. Freshwater ecosystems are generally inhabited by similar microbial groups (i.e., "typical freshwater bacteria"; Zwart et al. [51]) regardless of geographic location and characteristics, but with significant spatial and temporal variation within these groups [33]. These groups include typical freshwater Actinobacteria; alpha-, beta-, and gamma-proteobacteria; Cytophaga-Flavobateria-Bacteroides; and Verrucomicrobia $[33,51]$. Whether similar freshwater bacterial groups colonize filled vernal pools_-or whether they are inhabited by more specialized groups-is unknown. In either case, these communities may be used to examine biogeographic patterns in microorganisms. In particular, vernal pools can be considered habitable islands for microbes, and microbes may show geographical patterns in diversity and community composition [2, 14, 19, 32, 40].

In classical ecology, the latitudinal paradigm states that diversity gradually increases from the poles to the equator following a latitudinal gradient [23], and microbial ecologists have begun to examine whether microbes follow this pattern of biodiversity. However, whether such gradients result from a longer, more stable period of diversification in the tropics, higher speciation rates in the tropics, or lower extinction rates in comparison with temperate regions, still remains unresolved for larger organisms [29]. The presence and causes behind latitudinal patterns for microbes are even less clear. For example, Fuhrman et al. [15] detected a significant decrease in planktonic marine bacterial richness from the equator to the poles in the open ocean, but with notable variability in diversity at lower latitudes. Following a transect from mid-latitudes to the polar circles within lakes of South America and Antarctica, Schiaffino et al. [40] detected a decrease in evenness of microbial eukaryotes with decreasing latitude, but variations in richness were less clear. On land, Newsham et al. [32] detected a significant decrease in the richness of soil microfungi with increasing latitude along a $1650 \mathrm{~km}$ transect in Antarctica. These studies indicate that both aquatic and soil microbial communities may follow latitude-diversity gradients, but with notable differences in the shape and strength of these patterns-suggesting that additional research is needed. The distribution of vernal pools across the California province extends from 30 to $42^{\circ} \mathrm{N}(\sim 2400 \mathrm{~km})$, providing an opportunity to examine spatial patterns in diversity and community composition. Although this latitudinal range does not extend from the tropics to the poles, it provides a wide range of climatic conditions over which to test for the presence of diversity gradients.

Ecological studies have also observed a "distance-decay" pattern in many natural communities, in which community similarity decreases with increasing distance between locations [14]. Distance-decay patterns can be explained by the neutral theory that predicts community composition as a result of geographic proximity, where community similarity is driven by spatially limited dispersal, independent from environmental differences between sites [20,31], on the other hand, environmental conditions play a key role by "filtering" some taxa, in that microbial communities that are closer together in space may experience similar environments. The degree to which distance-decay relationships are shaped by dispersal capabilities (spatial distance), environmental differences, or a combination of both, may differ among ecosystems. For example, community dissimilarity among microbial communities in alpine lakes can be partly explained by the distance between sites [19], whereas temporary cave-pool microbial communities are explained by the sunlight exposure and environmental properties of the water [41]. For microbial communities in vernal pools of the California province, there is a lack of studies focusing on these ecological features. 
Under the premise that microorganisms can show distribution patterns similar to those exhibited by larger organisms, we tested the following hypotheses corresponding to specific paradigms established in classical and contemporary microbial ecology: (i) considering that vernal pools are subject to strong environmental selection [47], we hypothesized that water saturation and desiccation events will drive shifts in community composition from flooded pools to dry pools. Niche theory [42] states that the environment is the strongest driver for species to persist or recruit; in this context, moist and drought conditions may play a role in structuring microbial communities. If this is true, we expect to observe different microbial communities in saturated versus unsaturated soils, according to the seasonal-environmental variation in vernal pools, with a third community type present in the overlying water column. (ii) Considering that vernal pools are distributed latitudinally, we hypothesized the existence of a gradual increase in diversity of microorganisms along a transect from southern sites in Mexico to northern sites in the USA. (iii) In parallel, considering that vernal pools act as scattered or clustered habitat "islands" [47], we hypothesized that microbial communities will present spatial distribution patterns reflected in the community composition from each vernal pool. Thus, a distance-decay pattern is expected, where isolated vernal pools will have less similar microbial communities as a function of the space between pools. (iv) Finally, local environmental selection is likely to drive community composition as a result of the specific environmental properties across localities. We hypothesized that environmental variation in temperature and precipitation may be significant drivers of community similarity, explaining diversity between pools, sites, and regions, regardless of spatial proximity. Alternatively, dispersal capacity of microorganisms may be important in community assembly. If this is true, we expect to observe a relationship based mostly on spatial distances.

\section{Methods}

\section{Study Area}

As a Mediterranean-climate region, the study area is characterized by winter precipitation events and dry and hot summers. We sampled a latitudinal transect of $\sim 1300 \mathrm{~km}$, covering a significant portion of the geographical extension of the North American Mediterranean climate regime and the distribution of its vernal pools (Fig. 1). Sampling occurred in Baja California, Mexico, and California, USA. Each location varied in temperature and precipitation: temperature differences within the region range between $16^{\circ}$ and $18^{\circ}$ Celsius, and precipitation varies depending on subregions, but overall precipitation increases with latitude (data from BIOCLIM, Table 1). The vernal pools studied here belong to an "archipelago complex" (i.e., clusters of pools) or solitary vernal pools, often located at
Fig. 1 a North America Mediterranean-climate vernal pools. b Vernal pools extend along the Pacific West Coast in valleys and coastal mesas in California and Baja California. Climatic and geological features result in the formation of the vernal pools, which present $\mathbf{c}$ an aquatic phase characterized by flooding and soil saturation and d a terrestrial phase characterized by water evaporation and subsequent desiccation

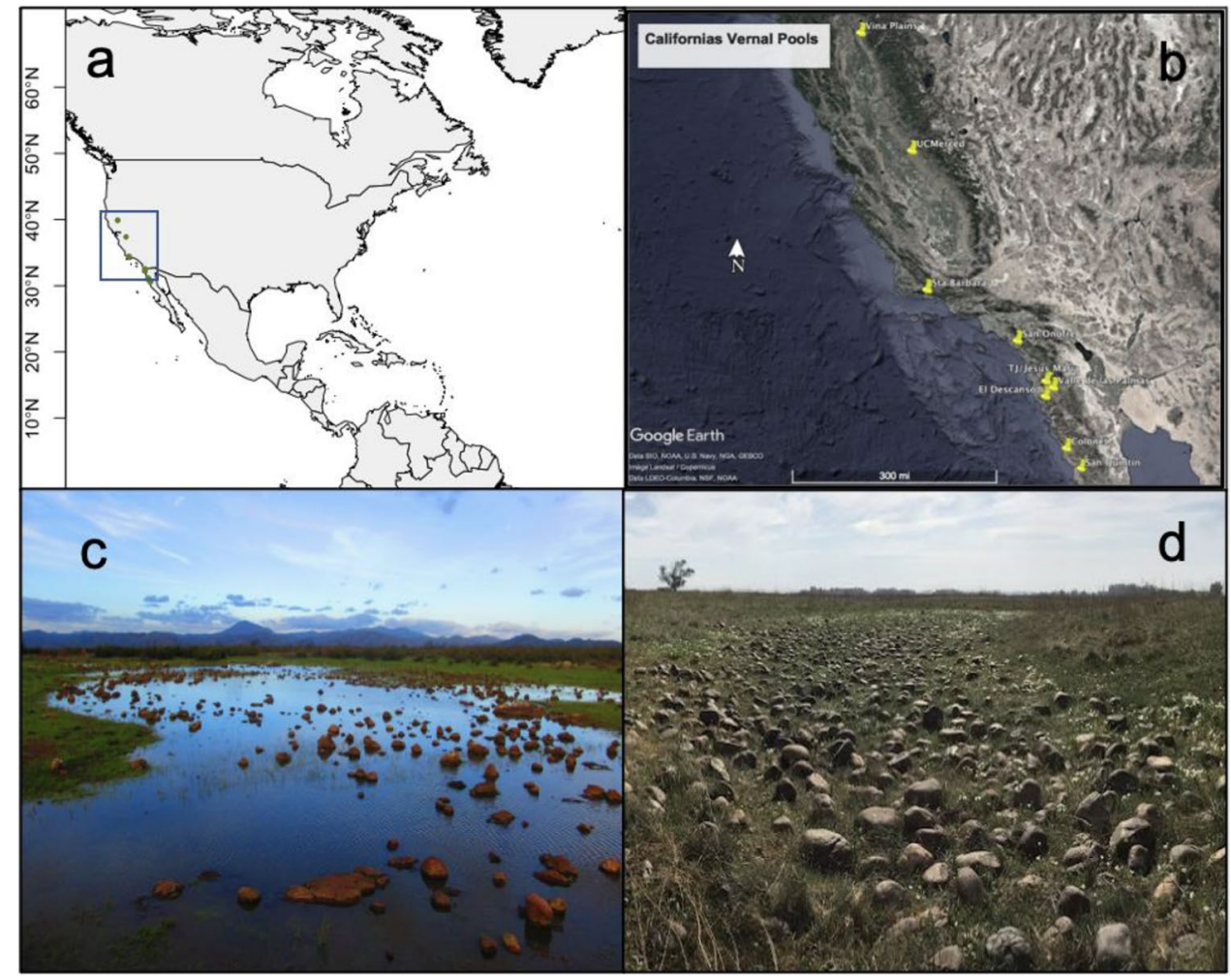


Table 1 30-year annual average temperature and precipitation of vernal pool regions and ID of the vernal pools sampled. Temperature (temp) is in Celsius and precipitation (precip) is in $\mathrm{mm}$. Data were obtained from BIOCLIM

\begin{tabular}{|c|c|c|c|c|c|c|}
\hline Vernal pool sites & $\begin{array}{l}\text { Sample type } \\
\text { collected }\end{array}$ & $\begin{array}{l}\text { Sample ID } \\
\text { number }\end{array}$ & Temp & Precip & Longitude & Latitude \\
\hline Vina Plains i & Water & 24 & 16.2 & 719 & -121.982942 & 39.901494 \\
\hline Vina Plains ii & Water & 25 & 16.2 & 719 & -121.983788 & 39.899747 \\
\hline Merced i & Water & 21 & 16.3 & 370 & -120.417208 & 37.376927 \\
\hline Merced ii & Water & 22 & 16.3 & 370 & -120.417668 & 37.377302 \\
\hline Merced iii & Water & 23 & 16.3 & 370 & -120.415969 & 37.375948 \\
\hline Santa Barbara i & Water & 17 & 15.2 & 468 & -119.86534 & 34.415124 \\
\hline Santa Barbara ii & Water & 18 & 15.2 & 468 & -119.866172 & 34.415841 \\
\hline Santa Barbara iii & Water & 19 & 15.2 & 468 & -119.867498 & 34.415982 \\
\hline Santa Barbara iv & Water & 20 & 15.2 & 468 & -119.868427 & 34.414142 \\
\hline \multirow[t]{3}{*}{ Tijuana "Jesus Maria Mesa" } & Water & 11,49 & 16.9 & 277 & -116.833829 & 32.50431 \\
\hline & Wet soil & 26 & & & & \\
\hline & Dry soil & 37 & & & & \\
\hline \multirow[t]{2}{*}{ El Descanso "Mesa" } & Water & 8,48 & 16.2 & 269 & -116.871812 & 32.177932 \\
\hline & Wet soil & 27 & & & & \\
\hline$(†)$ Valle De Las Palmas i & Dry soil & 38 & 16.6 & 282 & -116.73994 & 32.39779 \\
\hline (†)Valle De Las Palmas ii & Dry soil & 39 & 16.6 & 282 & -116.74147 & 32.39682 \\
\hline \multirow[t]{2}{*}{ Valle De Las Palmas iii } & Water & 2,14 & 16.3 & 340 & -116.64541 & 32.36915 \\
\hline & Wet soil & 29 & & & & \\
\hline \multirow[t]{3}{*}{ Valle De Las Palmas iv } & Water & 3,15 & 16.3 & 340 & -116.64582 & 32.36913 \\
\hline & Wet soil & 30 & & & & \\
\hline & Dry soil & 40 & & & & \\
\hline \multirow[t]{3}{*}{ Valle De Las Palmas v } & Water & 4,16 & 16.3 & 340 & -116.64631 & 32.36937 \\
\hline & Wet soil & 31 & & & & \\
\hline & Dry soil & 41 & & & & \\
\hline \multirow[t]{3}{*}{ Colonet i } & Water & 9 & 16.6 & 242 & -116.28739 & 31.09416 \\
\hline & Wet soil & 32 & & & & \\
\hline & Dry soil & 42 & & & & \\
\hline \multirow[t]{3}{*}{ Colonet ii } & Water & 12 & 16.6 & 242 & -116.28722 & 31.09355 \\
\hline & Wet soil & 33 & & & & \\
\hline & Dry soil & 43 & & & & \\
\hline \multirow[t]{3}{*}{ Colonet iii } & Water & 13 & 16.6 & 242 & -116.28787 & 31.09249 \\
\hline & Wet soil & 34 & & & & \\
\hline & Dry soil & 44 & & & & \\
\hline Colonet iv & Dry soil & 45 & 16.6 & 242 & -116.29275 & 31.05852 \\
\hline$(†)$ Colonet v & Dry soil & 46 & 16.6 & 242 & -116.293954 & 31.027036 \\
\hline$(†)$ Colonet vi & Dry soil & 47 & 16.6 & 242 & -116.293954 & 31.01739 \\
\hline Medina i & Water & 5 & 16.6 & 242 & -116.28147 & 31.030867 \\
\hline \multirow[t]{2}{*}{ Medina ii } & Water & 6 & 16.6 & 242 & -116.282222 & 31.030835 \\
\hline & Wet soil & 35 & & & & \\
\hline \multirow[t]{2}{*}{ Medina iii } & Water & 7 & 16.6 & 242 & -116.283296 & 31.030569 \\
\hline & Wet soil & 36 & & & & \\
\hline \multirow[t]{2}{*}{ San Quintin "Cerro las Torres" } & Water & 1,10 & 18.9 & 179 & -115.914153 & 30.584009 \\
\hline & Wet soil & 28 & & & & \\
\hline
\end{tabular}

$\dagger$, vernal pools destroyed due to urbanization flat ground on top of coastal mesas or valleys. From north to south, locations were annotated alongside with their climate and geographical position: in California, USA, (1) Vina Plains, (2) Merced, (3) Santa Barbara; in Baja
California, Mexico, (4) Mesa de Jesus Maria, Tijuana (5) El Descanso, (6) Valle de las Palmas, (7) Colonet (San Antonio del Mar), (8) Medina (Colonet mesa), and (9) Cerro las Torres, San Quintin. 


\section{Sampling Design}

To address our research interests regarding environmental selection and distribution patterns, we considered the first $15 \mathrm{~cm}$ from the soil surface to have a good representation of the soil microbiome [13]. We sampled each pool three times randomly from the center to the edge using a soil core, and homogenized the soil samples in sterile plastic bags. We collected one sample of $0.2 \mathrm{~g}$ of dry soil per pool in summer August 2016 for a total of 11 different pools. As a counterpart, we collected $0.2 \mathrm{~g}$ of "wet soil" from the same pools, but saturated with rainfall during the winter 2017 , for a total of 11 pools. Unfortunately, four vernal pools were lost due to urbanization during our sampling period between summer and winter, and due to federal regulations, vernal pool soils were not possible to access in the USA, leaving three locations without soil and wet soil samples (Table 1). Both sample types were stored in $2 \mathrm{ml}$ centrifuge tubes with dry ice before processing in the laboratory. In parallel, we also collected $100 \mathrm{ml}$ of water per vernal pool during the winters of 2016 and 2017, for a total of 27 water samples analyzed in this study; some pools in Valle de las Palmas and Colonet regions were sampled twice during 2017 corresponding to different rain events. We filtered the microorganisms from the water samples using Waltham brand® filters of $0.23 \mu \mathrm{m}$ pore size. After filtration, the filters were preserved in lysing tubes with a sucrose EDTA lysis solution and transported to the lab for DNA extractions [19]. Equipment was sterilized in between samples with 5\% bleach, $100 \%$ ethanol, and rinsed with MilliQ water five times. Soil and filters were processed for DNA extractions with QIAGEN DNeasy ${ }^{\circledR}$ extraction kits. Final DNA aliquots with $50 \mu \mathrm{l}$ per vernal pool were diluted to a final concentration of $20 \mathrm{ng}$ per $\mu 1$ for further amplification and sequencing.

\section{Microbial Community Analysis}

We examined dry soil, wet soil, and water samples via $16 \mathrm{~S}$ rDNA amplicon sequencing targeting the regions V4-V5 using the universal primers 515F-Y and 926R, which have been shown to effectively capture bacterial and archaeal diversity [36, 38]. Sample barcoding, PCR amplification, and sequencing (Illumina MiSeq) were performed at Argonne National Laboratories in Chicago, IL, following Earth Microbiome Project protocols. Sequences were obtained on the Illumina MiSeqTM platform in a $2 \times 250 \mathrm{bp}$ paired-end run. Demultiplexing and assignment of the amplicon sequence variants (ASVs) were performed using the Qiime2 (v.2021.4) platform, and DADA 2 was used as a quality control for chimeric reads [5]. Samples were rarefied to a sampling depth of 4000 sequences for the diversity analyses since the majority of samples contained between $1-6 \times 10^{4}$ sequence reads, with the exception of Vina Plains (ii) with 748 sequence reads; this water sample was omitted from the analysis. Alpha and beta diversity analyses were performed using dry soil, wet soil, and water samples; however, due to a lack of significant variation in the beta diversity of soil samples (see below), analyses to address distribution patterns were performed only with water samples.

\section{Diversity Analysis}

Analyses of amplicon sequence variants (ASVs) were performed using the platform Qiime2 (v.2021.4) designed for microbiome bioinformatics analyses; R studio (v.1.3.1093) packages qiime2-v0.99.1, phyloseq-v1.34.00, ggplot-v3.3.3, microbiome-v 1.14 .0 for additional statistical analyses and figures; and PASTV4.0 was used in parallel for ASV's diversity analyses [3, 4, 18, 25, 28, 46]. Alpha diversity metrics included Richness (observed taxa), Shannon (richness/evenness), Simpson (richness/abundances), Pielou (evenness), and ACE (richness and sampling coverage), and all of them were performed with Qiime2 and phyloseq. The KruskallWallis test was used to analyze differences in alpha diversity metrics between dry soil, wet soils, and water samples. Beta diversity was analyzed in Qiime2 and phyloseq using Bray-Curtis and unweighted Unifrac metrics of community dissimilarity; environmental information was included in community analyses using PCA and NMDS ordination methods. Permutation analysis of variance (PERMANOVA) and analysis of similarity (ANOSIM) (999 permutations) were used to correlate dissimilarity matrices for grouping significance and to make pairwise comparisons between sample types (dry soil vs. water, wet soil vs. water, and dry vs. wet soil). Alpha diversity was correlated with latitude and beta diversity values between water samples were correlated (r) against spatial distances between sites, with $P<0.05$ used to determine significance. Mantel tests (rho) were performed to correlate rarified taxa abundance similarity matrix values with temperature, precipitation, and geographical distance matrices.

\section{Results}

We tested multiple hypotheses through analysis of microbial communities inhabiting vernal pools. Overall, we found that the soil matrix and water column represented two adjacent but distinct habitat types, with different communities occupying different niches (rejecting the possibility of a single community transitory between the soil matrix and water column). Aquatic microbial communities displayed several significant patterns. We found a gradual increase in the diversity of microorganisms from southern sites in Mexico to northern sites in the USA, as well as a significant distancedecay pattern-with spatial proximity and environmental 
differences at site level explaining community similarity across vernal pools. Below we report observed patterns in microbial diversity and composition within vernal pools, followed by analysis of these patterns.

\section{Variations in Microbial Community Composition Between Soils, Wet soils, and Water in Vernal Pools}

Analysis of microbial communities within vernal pools spread throughout California, USA, and northern Baja California, Mexico, revealed multiple patterns in composition and diversity (Fig. 2). First, soil and water samples showed significant differences in microbial communities (Table 2). Beta diversity analysis (NMDS based on Bray-Curtis) also showed greater variability across aquatic microbial communities in comparison with soil microbial communities (Fig. 2a). Soil communities were more similar than water samples (outside of a few exceptions; see below), but with additional differences between dry and wet soils detected by PERMANOVA and ANOSIM (Table 2). Alpha diversity analyses of 22 soil samples, including dry soils and wet soils, were similar for all metrics of richness and abundance- - suggesting that dry and wet soils host similarly diverse microbial communities across different sites (Fig. 2b). In contrast, aquatic communities displayed lower alpha diversity than soils (Fig. 2b), but greater beta diversity between these communities (Fig. 2a).

\section{Microbial Taxa in Soil and Water}

Bacteria were present in both soils and water, but with marked differences between sample types (as the beta diversity analyses above indicate). We found 42 phyla in total, and the most abundant were Proteobacteria and Bacteroidetes (Fig. 3a). Water was dominated by a few phyla, primarily
Fig. 2 Microbial community analysis. a Beta Diversity: NMDS ordination analysis based on Bray-Curtis similarity coefficients. Soils and water have distinct microbial communities. b Alpha diversity by four different measures and by sample type. Soils (dry and wet) showed higher diversity in comparison with the water column: soil-water $H=18.9$, $P=0.000013$; wet soil-water $H=22.5, P=0.000002$; soil-wet soil $H=0.13, P=0.71$

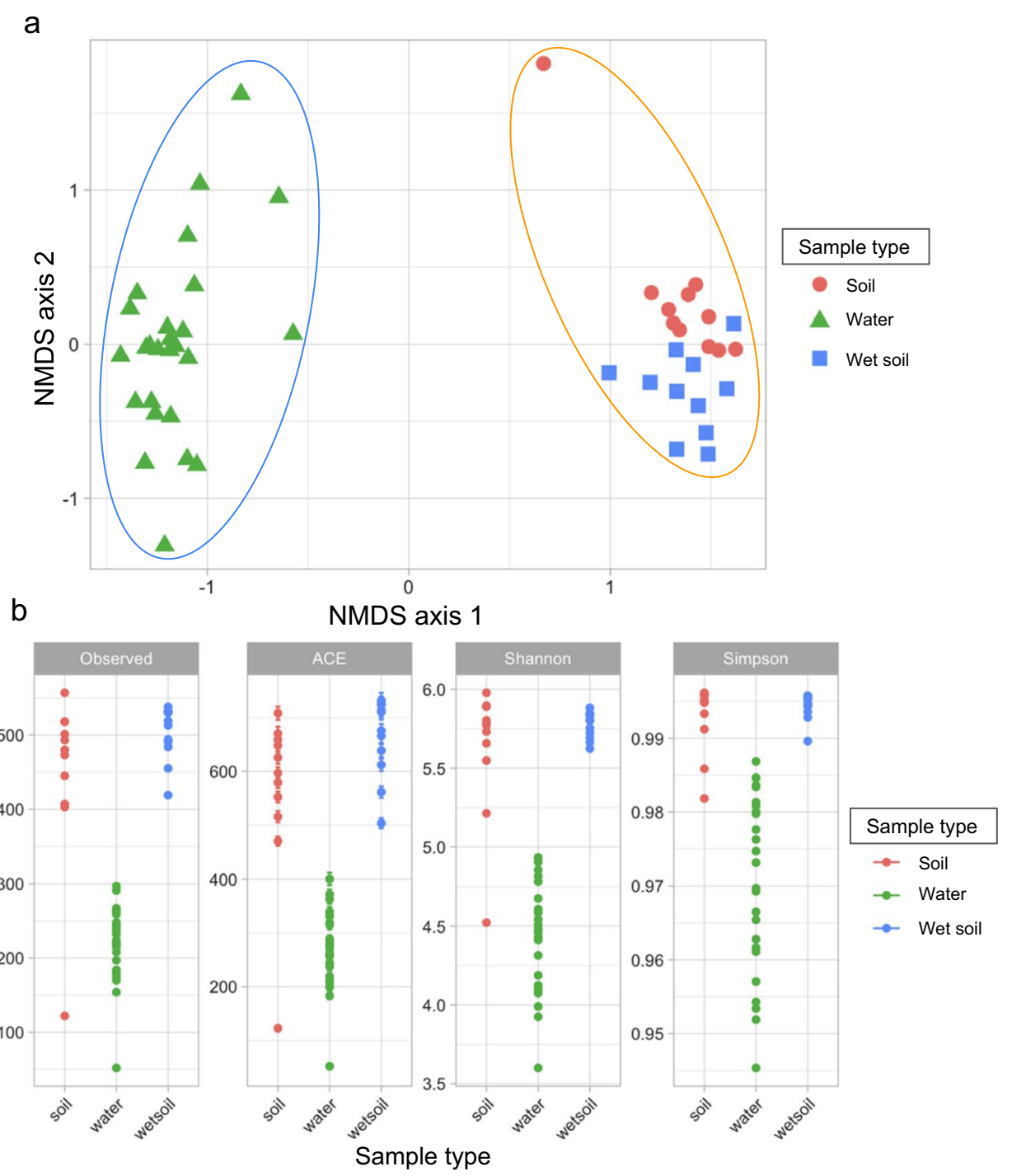


Table 2 Group significance by permutation analysis of variance (PERMANOVA) and analysis of similarity (ANOSIM) between sample types

\begin{tabular}{llll}
\hline & Dry soil-water & Wet soil-soil & Water-wet soil \\
\hline PERMANOVA & & & Pseudo $F=4.753768, P=0.001$ \\
Bray-Curtis & Pseudo $F=5.265952, P=0.001$ & Pseudo $F=1.633980, P=0.002$ & Pseudo $F=8.048377, P=0.001$ \\
Unweighted-Unifrac & Pseudo $F=7.857370, P=0.001$ & Pseudo $F=1.632099, P=0.001$ & \\
ANOSIM & & & $R=0.97, P=0.001$ \\
Bray-Curtis & $R=0.98, P=0.001$ & $R=0.21, P=0.002$ & $R=0.90, P=0.001$ \\
Unweighted-Unifrac & $R=0.89, P=0.001$ & $R=0.28, P=0.001$ & \\
\hline
\end{tabular}

Bacteroidetes and Proteobacteria, followed by Verrucomicrobia and Actinobacteria in lower proportions.

Soil was dominated by Proteobacteria, followed by Actinobacteria, Acidobacteria, Bacteroidetes, Cyanobacteria, Firmicutes, Verrucomicrobia, Planctomycetes, and Gemmatimonadetes. Our analysis revealed Fusobacteria as a rare phylum associated only with water samples; rare phyla associated with soil samples included AD3, BHI80139, GOUTA4, Kazan 3B28, MVP21, OP3WS2, WS3, WS4, WS6, and WWE1. Differences between soil and water were more clearly evident at the class level, with alpha-, beta-, and gamma-proteobacteria being more common in water than in either dry or wet soil (Fig. 3b). Within the Bacteroidetes phylum, Cytophagia, Flavobacteria, and Sphingobacteria were likewise more common in water (Fig. 3c). In contrast, soils showed a more even distribution of all classes of Proteobacteria and Bacteroidetes.

Archaea were detected almost exclusively in soils, comprising the phyla Crenarchaeota, Euryarchaeota, and Pavarcheota. Archaea being mostly limited to soils suggests that aquatic archaea are less likely to inhabit vernal pool waters (Fig. 4). At the class level, archaeal diversity was dominated by Thaumarchaeota followed by Methanomicrobia, Thermoplasmata, MCG, and Parvarchaea.
Fig. 3 Taxonomic composition in water and soil samples, illustrating greater differences between water and soils than between wet and dry soils. a The relative abundance at phylum level across sample types; b Proteobacteria abundances across sample types; and $\mathbf{c}$ Bacteroidetes abundances across sample types
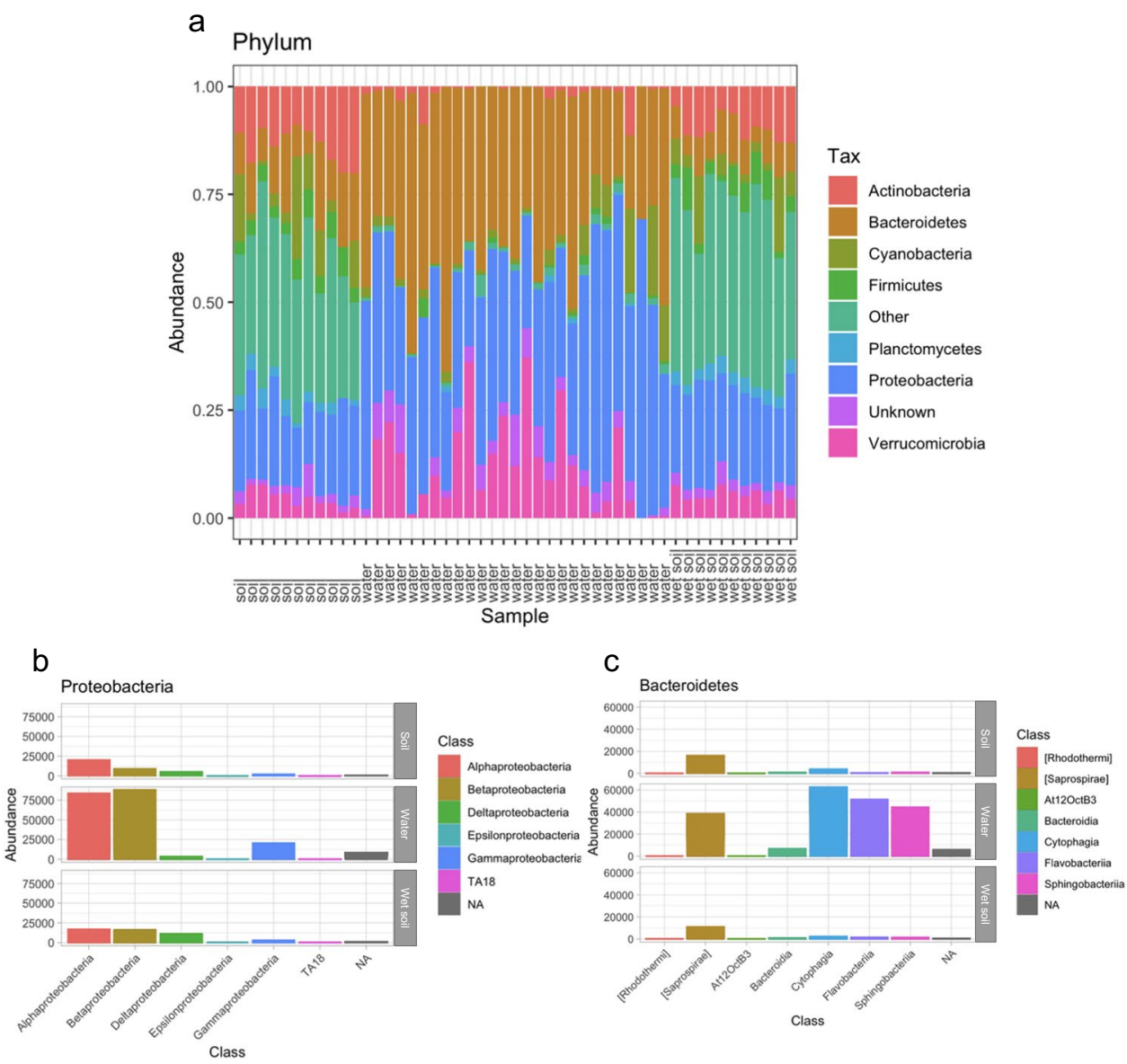


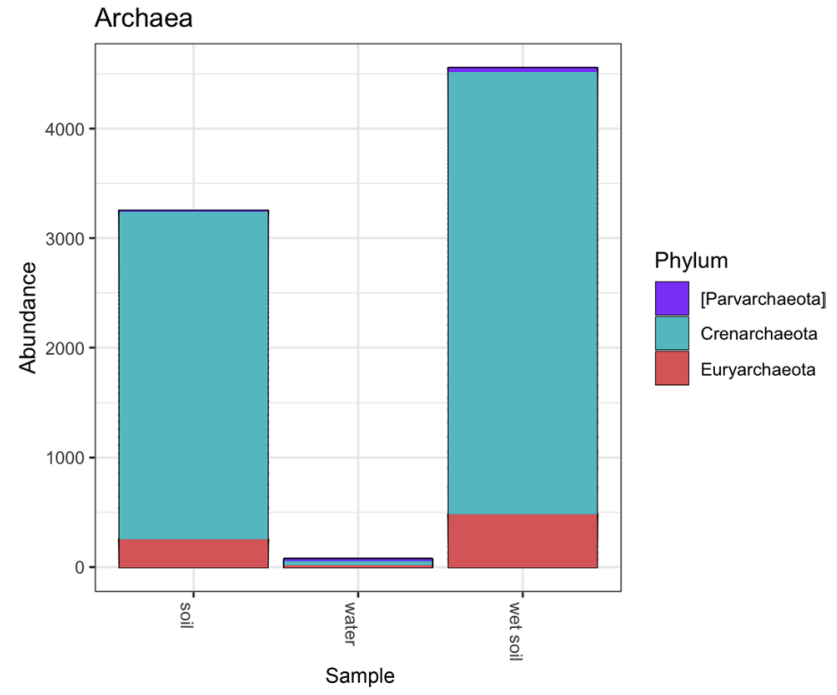

Fig. 4 Taxa abundance of Archaea at phylum level between soil, wet soil, and water samples. The brackets indicate the taxonomic name is contested, morphology-based taxonomy doesn't always align with phylogeny

Overall, diversity was higher in soils than water, and dominant groups appeared consistently, even within those samples with lower numbers of sequence reads.

\section{The Latitudinal Diversity Gradient in Vernal Pool Microbial Communities}

We tested for several biogeographic patterns in vernal pool microbial communities. First, the general increase in biodiversity from the poles to the equator is what defines the concept of the latitudinal diversity gradient, and community composition is expected to transition gradually in sites along this gradient. We found a significant latitudinal diversity gradient in vernal pool microbes; however, this was only significant for aquatic communities, and was also inverted, with higher diversity at higher latitudes (Fig. 4). Additionally, this pattern was only observed for diversity metrics based on evenness, with a significant relationship between latitude and Pielou's evenness, and a nearly

Table 3 Correlation coefficients between diversity and latitude; significant Pearson's $r$ for the alpha diversity-latitude relationship indicate a positive relationship between latitude and Pielou's evenness

\begin{tabular}{lllll}
\hline & ASV richness & Shannon & Pielou & ACE \\
\hline Significance $\boldsymbol{p}$ & 0.95 & $\mathbf{0 . 0 5 5}$ & $\mathbf{0 . 0 3 6}$ & 0.785 \\
Distribution $\boldsymbol{t}$ & -0.054941 & $\mathbf{2 . 0 1 3 1}$ & $\mathbf{2 . 2 1 1 4}$ & -0.27562 \\
Pearson's $\boldsymbol{r}$ & -0.01121413 & $\mathbf{0 . 3 8}$ & $\mathbf{0 . 4 1 1}$ & -0.05617155 \\
\hline
\end{tabular}
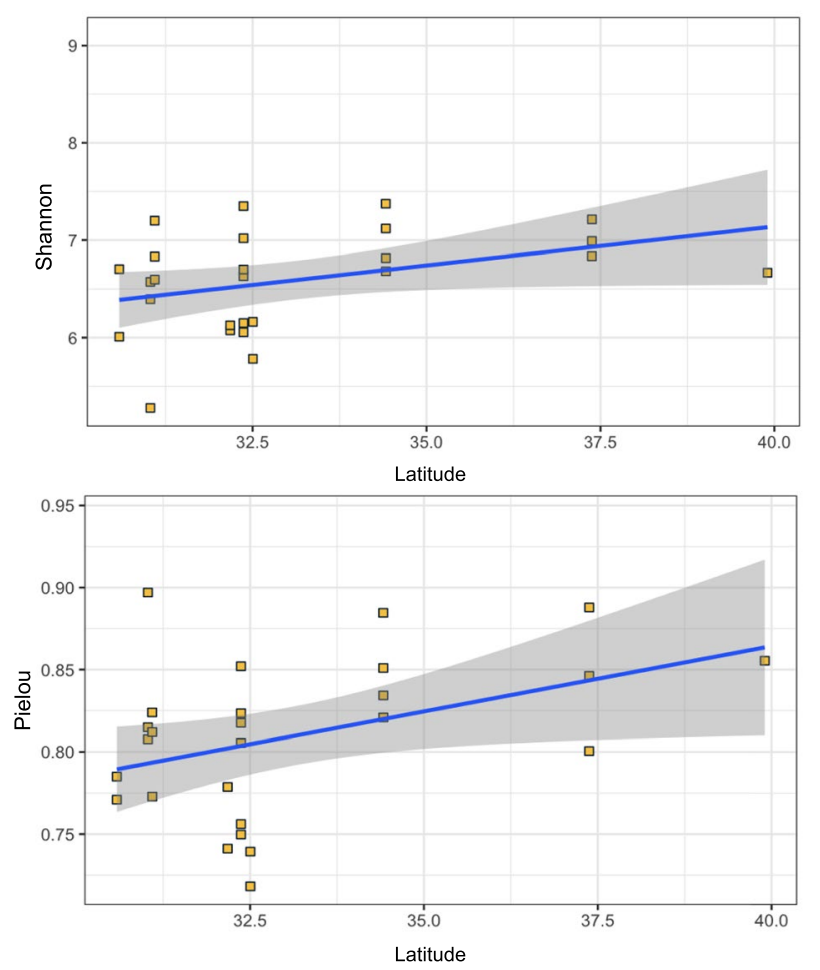

Fig. 5 Diversity along a latitudinal gradient is inverted for aquatic prokaryotes in vernal pools. The scatter plots show Shannon index (a) and Pielou's evenness index (b) in vernal pools plotted across latitude (yellow dots)

significant relationship for the Shannon index (Table 3, Fig. 5).

\section{Distance Decay: Dispersal Capabilities vs Environmental Selection}

Our results also showed community composition strongly explained by the distances among sites $\left(R^{2}=0.5625\right.$; $P<0.01$ Fig. 6), suggesting that community isolation is driven by dispersal limitation or environmental differences between sites. To test whether dispersal limitation (geographical distance) or environmental filtering were drivers of community composition, we analyzed the correlation (rho) between climatic parameters, spatial distances, and community dissimilarity indices. We tested if the microbial community composition was correlated with mean annual precipitation and temperature. Temperature did not influence community composition. The Mantel test based on Spearman's rank correlation (permutations $=9999$ ) between mean precipitation and taxa distribution (Bray-Curtis dissimilarity) showed significant correlation including all samples, soil and water $(r: 0.1269$, $P=0.0249)$. Precipitation also explained the microbial community composition for water samples $(r: 0.4324$, 
Fig. 6 Dissimilarity in aquatic microbial communities in vernal pools increases with distance between sites; each point represents a specific value given by the Bray-Curtis dissimilarity index between two vernal pool microbial communities at varied distances

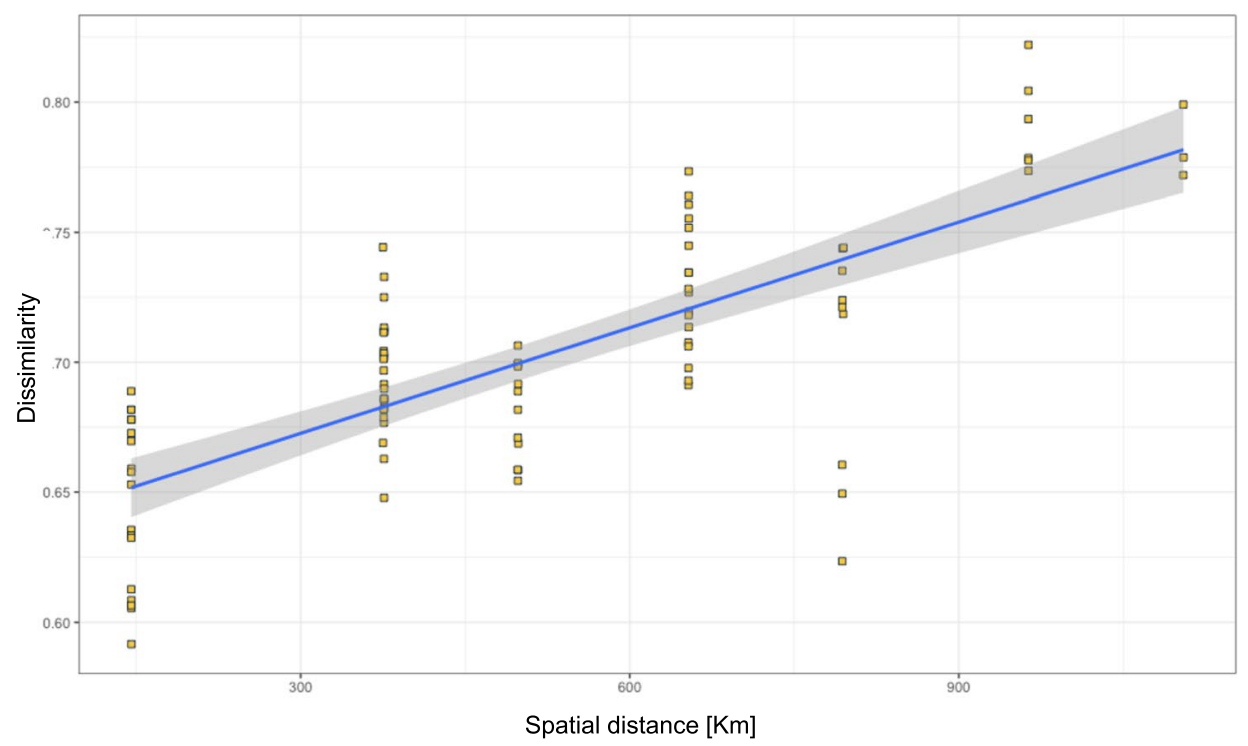

$P=8 \mathrm{e}-04)$. On the other hand, geographical distance $(r$ : $0.32, P=00.02$ ) — which addresses the influence of dispersal limitation-also significantly explained the assembly of communities (Table 4). A combination of local precipitation and geographical distance between sites was therefore significantly related to community composition.

\section{Discussion}

Our analysis of microbial communities in vernal pools provides additional evidence that microorganisms can display the same natural patterns as larger organisms [12, 26, 50]. However, some interesting attributes were not expected: for example, despite strong seasonal variations in vernal pools, their aquatic microbial communities were similar to other freshwater ecosystems. Vernal pools evidently represent isolated aquatic "islands" surrounded by completely terrestrial ecosystems. This raises interesting questions, such as where, when, and how freshwater microbes colonize vernal pools. Related to this, the geographical distribution of pools across Baja California and California was important for aquatic microbial community assembly, but not for soil microbial communities. Several biogeographical patterns were visible and significant within water, despite some limitations and caveats that we discuss below.

\section{Implications of Vernal Pool Microbial Communities Resembling Other Freshwater Ecosystems}

We expected that vernal pool variability (desiccation to inundation) could potentially select for unique taxa, but we found that vernal pool microbial communities in water were dominated by "typical" freshwater bacterial taxa [21, 33, 34, 51]. These groups are commonly found across a wide range of freshwater ecosystems, and specifically include Bacteroidetes and Proteobacteria (Fig. 3). For example, we found that eight of the most common ASVs in water (each $>1 \%$ of all sequences, with higher abundances in some individual pools) were $98.3-100 \%$ identical to database sequences found in other freshwater ecosystems (Table S1). This included sequences from a large-scale study of freshwater bacterioplankton [8], as well as multiple whole genomes recovered from other freshwater ecosystems. Actinobacteria are also common in freshwater [33], and were present (albeit less abundant overall) in vernal pools. Even within those

Table 4 Mantel test summary: correlation between similarity matrix based on rarified abundances of microbial taxa, and precipitation or geographical distances (spatial distances)

\begin{tabular}{llll}
\hline Matrix analyzed & (rho) & Significance $p$ & Permutations \\
\hline Precipitation/total.abund & $r: 0.1269$ & $p=0.0249$ & 9999 \\
Precipitation/water.abund & $r: 0.4324$ & $p=8 \mathrm{e}-04$ & 9999 \\
Geographical.distance/water.abund & $r: 0.3203$ & $p=0.0203$ & 9999 \\
\hline
\end{tabular}


samples with lower sequence reads (water sample VP025), these common freshwater taxa were dominant.

These findings suggest that common freshwater microbes are able to colonize vernal pools each year in spite of the ephemeral nature of the pools. How exactly vernal pools are populated by common freshwater taxa, and whether vernal pools contain endemic archaeal and bacterial communities are interesting questions worthy of additional study and experimentation. Freshwater bacteria are notably widespread [51], and the attributes of vernal pools may help provide insight into their broad geographic distribution and the connectivity between freshwater ecosystems via animals or air. For example, possible transport pathways could involve larger organisms that use the vernal pools as a place of rest and breeding, such as migratory birds. Amphibians breeding in stock ponds might also play a role as a vector for microbial taxa, transporting and connecting permanent freshwaters with vernal pools. Additionally, rain might play an important role in transporting microorganisms [11]. On the other hand, these Mediterranean-climate vernal pools have a cemented layer preventing interchangeable flows from subsoil to surface, which reduces the possibility of groundwater connectivity. Considering the impact of anthropogenic activities over the landscape - where some vernal pools have been transformed into stock ponds, and other human-made water reservoirs are located nearby - anthropogenic activities may also be relevant in the context of microbial distributions and their alterations [22]. Finally, some taxa may also disperse widely by wind, and environmental constraints between habitats might shape microbial communities [10].

\section{Lack of Significant Biogeographic Patterns in Soil Microbial Communities}

A main goal of this research was to determine if microbial communities in vernal pools show distribution patterns previously recorded in other microbial systems and for larger organisms. We detected several patterns in microbial communities (e.g., a significant latitude-diversity gradient and distance decay)—but these patterns were only significant for aquatic communities. In the case of soil, our results indicate that conditions in vernal pool soils select for consistent microbial communities across distant locations, with the exception of one sample located at the southern edge of our region of study (soil sample 46-ColonetV, Fig. 2 outlier). Several factors might have obscured our ability to detect significant patterns in soil, if present. One issue is the presence of relic DNA coming from extracellular or non-intact cells, which can account for 40 to $80 \%$ of prokaryotic DNA in soils, and can persist in soil for weeks to years [24]. Another possibility is that precipitation events have an impact on the microbial community by "resetting" a well-established microbial community. In combination with physicochemical properties (i.e., cation exchange capacity and $\mathrm{pH}$ ), this could have a direct effect on the recovery of eDNA [6, 24]. Microbial adaptations to survive long periods of desiccation and the transition from flooding to desiccation could result in low variation from one phase to another [43]. Finally, our soil sampling was necessarily more spatially limited than our water sampling, and additional sampling could capture greater community variation. Including other molecular techniques such as metatranscriptomic sequencing may also help reveal additional patterns, especially within soil microbial communities.

\section{Inverted Latitudinal Gradient}

One significant pattern detected in vernal pool water was a significant latitude-diversity relationship, but this was inverted, with higher evenness at higher latitudes. Some ecological explanations for such inverted gradients rely on specific interactions between taxa-for example, predation-and theories of energy around environmental systems [30]. We suggest that the most likely explanation for this relationship is related to precipitation, as much higher precipitation rates occur at higher latitudes along our sampling transect, previous studies have addressed a climate-latitudinal diversity gradient in other temporal freshwater bodies [23]. As a result, vernal pools in southern latitudes have shorter periods of inundation, and dispersal may be diminished due to the absence of nearby water bodies. This may result in more uneven communities. Based on the limited energy hypothesis behind latitudinal diversity - which states that sunlight is directly correlated with plant productivity and species biodiversity [30] — another possible explanation is that higher primary production in Northern California is a reflection of longer growth periods (due to greater precipitation rates), with inundated vernal pools lasting longer and favoring higher diversity. Moreover, the inverse prokaryotic diversity gradient observed among these study sites may be associated with eukaryotic diversity patterns, which we did not evaluate.

\section{Significant Distance Decay in Vernal Pool Aquatic Microbial Communities}

Like islands in the ocean, vernal pools are ideal for understanding ecological and evolutionary processes that shape biodiversity. The pattern we described in this study has been found in freshwater bodies, where the existing pattern of dissimilarity (community isolation) is a product of both environmental differences and the spatial distance between sites [19,41]. Our results also partially explain the distance-decay pattern based on both climatic variation and dispersal capabilities, indicating that environmental selection and microbial dispersal are both important for vernal 
pool aquatic microbial community assembly. Further studies should directly address if surrounding freshwater bodies, precipitation, atmospheric deposition, or large organisms provide vernal pools with freshwater taxa. Related to this, interspecific interactions-such as predation or other symbiotic relationships-may also affect vernal pool microbial communities to varying degrees. Stochastic events and anthropogenic influences may also be important [22, 50], for example, across our sampling gradients, pools at southern latitudes remain more pristine. Given their inherent attributes and significant distance decay in microbial community similarity, vernal pools appear to be an effective study system for studying microbial community assembly.

\section{Conclusions}

This research is the first formal attempt to characterize and quantify microbial communities in Mediterranean-climate vernal pools in North America, providing initial insight into the microbial ecology of these endangered ecosystems. Overall, our study indicates that environmental selection plays an important role in defining distinct vernal pool microbial communities in soil and water. Aquatic communities in vernal pools exhibit a non-traditional latitudinal diversity pattern, which may be partially explained by precipitation patterns. Dispersal limitation is important as well, as a combination of spatial and environmental variation shaping the assembly of vernal pool aquatic microbial communities. Whether such patterns are consistent over longer time periods, and what mechanisms are involved to assemble community differences observed here are important future research avenues. Vernal pools are well-known for being inhabited by organisms adapted to both aquatic and terrestrial conditions (e.g., plants), with life cycles modified in order to survive shifts of inundation and total desiccation in a short period of time. Occasionally this transition occurs quickly, with intermittent precipitation and evapotranspiration happening rapidly within days. Exploring these transitions at different temporal scales may provide insights about "amphibious behavior" in microorganisms inhabiting these ecosystemsi.e., the ability to survive in both soil and water. Finally, additional spatial, temporal, and biological (e.g., plant and animal hosts and vectors) sampling may reveal new biological discoveries in these endangered vernal pool ecosystems.

Supplementary Information The online version contains supplementary material available at https://doi.org/10.1007/s00248-021-01941-2.

Acknowledgements We thank the staff members from the University of California, Merced (UCM) School of Natural Science and the School of Engineering, who provided equipment and advice to carry out the fieldwork. "El Jardin de San Quintin" Civil Association (A.C.) and "Nativos de las Californias" Civil Association (A.C.), provided accommodations, human resources, and transportation to each locality in Baja California during fieldwork. The Nature Conservancy at Vina Plains and the UCM Vernal Pools and Grassland Reserve provided access to their protected areas. Dr. Merixell Riquelme from CICESE provided laboratory space and equipment to perform DNA extractions in Baja California. We give special thanks to Robert Schlising, Jon Keeley, Thomas Harmon, Iolanda Ramalho da Silva, James Riley, Susana Alfaro, Daniel Toews, and Lorenzo Booth, who actively participated in the realization, instrumentation, and advice during this study. CONACyT and UC Mexus provided support to JAMMM, including extra support during the COVID-19 pandemic, as well as the UCM Environmental Systems Graduate Group. Support for this project was also provided to ACF, JMB, and JPS from a UCM Academic Senate Faculty Research Grant and by a University of California President's Research Catalyst Award (CA-16-376437) to the University of California Conservation Genomics Consortium; and by a grant from the US Fish and Wildlife Service and Bureau of Reclamation's Central Valley Project Conservation Program (CVPCP) and Central Valley Project Improvement Act Habitat Restoration Program (HRP) (CESU-R17AC00044) to JPS. Finally, we thank the three anonymous reviewers whose comments greatly improved the manuscript.

Author Contribution JAMMM planned the research, designed the sampling, and performed the laboratory work. JAMMM and JMB analyzed the data. JAMMM, JMB, JPS, and ACF wrote the article.

Funding CONACyT-UC Mexus 2015-2020 doctoral fellowship award; 2016 COR research funding UC Merced; University of California President's Research Catalyst Award (CA-16-376437); US Fish and Wildlife Service and Bureau of Reclamation's Central Valley Project Conservation Program (CVPCP); Central Valley Project Improvement Act Habitat Restoration Program (HRP) (CESU-R17AC00044).

\section{Availability of Data and Material DRYAD.}

Code Availability Not applicable.

\section{Declarations}

Ethics Approval and Consent to Participate Not applicable.

Consent for Publication All authors agreed to publish this manuscript to Microbial Ecology.

Conflict of Interest The authors declare no competing interests.

Open Access This article is licensed under a Creative Commons Attribution 4.0 International License, which permits use, sharing, adaptation, distribution and reproduction in any medium or format, as long as you give appropriate credit to the original author(s) and the source, provide a link to the Creative Commons licence, and indicate if changes were made. The images or other third party material in this article are included in the article's Creative Commons licence, unless indicated otherwise in a credit line to the material. If material is not included in the article's Creative Commons licence and your intended use is not permitted by statutory regulation or exceeds the permitted use, you will need to obtain permission directly from the copyright holder. To view a copy of this licence, visit http://creativecommons.org/licenses/by/4.0/. 


\section{References}

1. Becking LGMB (1934) Geobiologie of inleiding tot de milieukunde. Van Stockum

2. Beisner BE, Peres-Neto PR, Lindström ES et al (2006) The role of environmental and spatial processes in structuring lake communities from bacteria to fish. Ecology 87:2985-2991. https://doi. org/10.1890/0012-9658(2006)87[2985:troeas]2.0.co;2

3. Bisanz JE (2018) qiime2R: importing QIIME2 artifacts and associated data into R sessions https://github.com/jbisanz/qiime2R

4. Bolyen E, Rideout JR, Dillon MR et al (2019) Reproducible, interactive, scalable and extensible microbiome data science using QIIME 2. Nat Biotechnol 37:852-857. https://doi.org/10.1038/ s41587-019-0209-9

5. Callahan BJ, Mcmurdie PJ, Rosen MJ et al (2016) DADA2: highresolution sample inference from Illumina amplicon data. Nat Methods 13:581-583. https://doi.org/10.1038/nmeth.3869

6. Carini P, Marsden PJ, Leff JW et al (2016) Relic DNA is abundant in soil and obscures estimates of soil microbial diversity. Nat Microbiol. https://doi.org/10.1038/nmicrobiol.2016.242

7. Comeau AM, Harding T, Galand PE et al (2012) Vertical distribution of microbial communities in a perennially stratified Arctic lake with saline, anoxic bottom waters. Sci Rep. https://doi.org/ 10.1038/srep00604

8. Crump BC, Peterson BJ, Raymond PA et al (2009) Circumpolar synchrony in big river bacterioplankton. Proc Natl Acad Sci 106:21208-21212. https://doi.org/10.1073/pnas.0906149106

9. Dickey JR, Swenie RA, Turner SC et al (2021) The utility of macroecological rules for microbial biogeography. Front Ecol Evol. https://doi.org/10.3389/fevo.2021.633155

10. Dueker ME, French S, O'Mullan GD (2018) Comparison of bacterial diversity in air and water of a major urban center. Front Microbiol. https://doi.org/10.3389/fmicb.2018.02868

11. Evans C, Coombes P, Dunstan R (2006) Wind, rain and bacteria: the effect of weather on the microbial composition of roof-harvested rainwater. Water Res 40:37-44. https://doi.org/ 10.1016/j.watres.2005.10.034

12. Fierer N, Jackson RB (2006) The diversity and biogeography of soil bacterial communities. Proc Natl Acad Sci 103:626-631. https://doi.org/10.1073/pnas.0507535103

13. Fierer N, Schimel JP, Holden PA (2003) Variations in microbial community composition through two soil depth profiles. Soil Biol Biochem 35:167-176. https://doi.org/10.1016/s00380717(02)00251-1

14. Finkel OM, Burch AY, Elad T et al (2012) Distance-decay relationships partially determine diversity patterns of phyllosphere bacteria on tamrix trees across the Sonoran Desert. Appl Environ Microbiol 78:6187-6193. https://doi.org/10.1128/aem. 00888-12

15. Fuhrman JA, Steele JA, Hewson I et al (2008) A latitudinal diversity gradient in planktonic marine bacteria. Proc Natl Acad Sci 105:7774-7778. https://doi.org/10.1073/pnas.0803070105

16. Gilbert JA, Jansson JK, Knight R (2018) Earth microbiome project and global systems biology. mSystems. doi: https://doi.org/ 10.1128/msystems.00217-17

17. Hanson C, Fuhrman J, Horner-Devine M et al (2012) Beyond biogeographic patterns: processes shaping the microbial landscape. Nat Rev Microbiol 10:497-506. https://doi.org/10.1038/ nrmicro2795

18. Hammer $\emptyset$, Harper DAT, Ryan PD. (2001) PAST: PALEONTOLOGICAL STATISTICS SOFTWARE PACKAGE FOR EDUCATION AND DATA ANALYSIS. http://palaeo-electronica. org/2001_1/past/issue1_01.htm.

19. Hayden CJ, Beman JM (2015) Microbial diversity and community structure along a lake elevation gradient in Yosemite
National Park, California, USA. Environ Microbiol 18:17821791. https://doi.org/10.1111/1462-2920.12938

20. Hubbell SP (2005) Neutral theory in community ecology and the hypothesis of functional equivalence. Funct Ecol 19:166172. https://doi.org/10.1111/j.0269-8463.2005.00965.x

21. Kasalický V, Jezbera J, Hahn MW, Šimek K (2013) The diversity of the limnohabitans genus, an important group of freshwater bacterioplankton, by characterization of 35 isolated strains. PLoS ONE. https://doi.org/10.1371/journal.pone.0058209

22. Kiersztyn B, Chróst R, Kaliński T et al (2019) Structural and functional microbial diversity along a eutrophication gradient of interconnected lakes undergoing anthropopressure. Sci Rep. https://doi.org/10.1038/s41598-019-47577-8

23. Kneitel JM (2016) Climate-driven habitat size determines the latitudinal diversity gradient in temporary ponds. Ecology. https://doi.org/10.1890/15-1584

24. Lennon J, Muscarella M, Muscarella S, Lehmkuhl B (2017) How, when, and where relic DNA biases estimates of microbial diversity. doi: https://doi.org/10.1101/131284

25. Lahti L, et al. (2017). Tools for microbiome analysis in R. Version 1.14.0. URL: http://microbiome.github.com/microbiome

26. Martiny JBH, Bohannan BJ, Brown JH et al (2006) Microbial biogeography: putting microorganisms on the map. Nat Rev Microbiol 4:102-112. https://doi.org/10.1038/nrmicro1341

27. Mccarthy JM, Gumbricht T, Mccarthy T et al (2003) Flooding patterns of the Okavango Wetland in Botswana between 1972 and 2000. AMBIO 32:453-457

28. Mcmurdie, Holmes (2013) phyloseq: an R package for reproducible interactive analysis and graphics of microbiome census data. PLoS ONE. 8(4):e61217

29. Mittelbach GG, Schemske DW, Cornell HV et al (2007) Evolution and the latitudinal diversity gradient: speciation, extinction and biogeography. Ecol Lett 10:315-331. https://doi.org/10.1111/j. 1461-0248.2007.01020.x

30. Morales-Castilla I, García-Valdés R (2014) Reverse latitudinal diversity gradients, exceptions that prove the rule? Ecosistemas 23:4-12. https://doi.org/10.7818/ecos.2014.23-1.02

31. Nekola JC, White PS (1999) The distance decay of similarity in biogeography and ecology. J Biogeogr 26:867-878. https://doi. org/10.1046/j.1365-2699.1999.00305.x

32. Newsham K, Hopkins D, Carvalhais L et al (2016) Relationship between soil fungal diversity and temperature in the maritime Antarctic. Nature Clim Change 6:182-186. https://doi.org/10. 1038/nclimate2806

33. Newton RJ, Jones SE, Eiler A et al (2011) A guide to the natural history of rreshwater lake bacteria. Microbiology and Molecular Biology Reviews 75:14-49. https://doi.org/10.1128/mmbr. 00028-10

34. Nuy JK, Hoetzinger M, Hahn MW et al (2020) Ecological differentiation in two major freshwater bacterial taxa along environmental gradients. Front Microbiol. https://doi.org/10.3389/fmicb. 2020.00154

35 O'Malley (2008) 'Everything is everywhere: but the environment selects': ubiquitous distribution and ecological determinism in microbial biogeography. Studies in History and Philosophy of Science Part C: Studies in History and Philosophy of Biological and Biomedical Sciences 39(4):314-325. https://doi.org/10.1016/j. shpsc.2008.06.005

36. Parada AE, Needham DM, Fuhrman JA (2016) Every base matters: assessing small subunit rRNA primers for marine microbiomes with mock communities, time series and global field samples. Environ Microbiol 18(5):1403-1414. https://doi.org/ 10.1111/1462-2920.13023

37. Parolin P, Simone OD, Haase K et al (2004) Central Amazonian floodplain forests: tree adaptations in a pulsing system. Bot Rev 
70:357-380. https://doi.org/10.1663/0006-8101(2004)070[0357: caffta]2.0.co;2

38. Quince C, Lanzen A, Davenport RJ, Turnbaugh PJ (2011) Removing noise from pyrosequenced amplicons. BMC Bioinformatics. https://doi.org/10.1186/1471-2105-12-38

39. Rusch A, Walpersdorf E, Debeer D et al (2005) Microbial communities near the oxic/anoxic interface in the hydrothermal system of Vulcano Island, Italy. Chem Geol 224:169-182. https://doi.org/ 10.1016/j.chemgeo.2005.07.026

40. Schiaffino MR, Lara E, Fernández LD et al (2016) Microbial eukaryote communities exhibit robust biogeographical patterns along a gradient of Patagonian and Antarctic lakes. Environ Microbiol 18:5249-5264. https://doi.org/10.1111/1462-2920. 13566

41. Shabarova T, Pernthaler J (2010) Karst pools in subsurface environments: collectors of microbial diversity or temporary residence between habitat types. Environ Microbiol 12:1061-1074. https:// doi.org/10.1111/j.1462-2920.2009.02151.x

42. Tilman D (2004) Niche tradeoffs, neutrality, and community structure: a stochastic theory of resource competition, invasion, and community assembly. Proc Natl Acad Sci 101:10854-10861. https://doi.org/10.1073/pnas.0403458101

43. Timoner X, Buchaca T, Acuña V, Sabater S (2014) Photosynthetic pigment changes and adaptations in biofilms in response to flow intermittency. Aquat Sci 76:565-578. https://doi.org/10.1007/ s00027-014-0355-6

44. Vinogradskij Sergej Nikolajevič. (1889) Recherches sur les organismes de la nitrification. Impr. Charaire
45. Wang Y, Bradford SA, Šimůnek J (2013) Transport and fate of microorganisms in soils with preferential flow under different solution chemistry conditions. Water Resour Res 49:2424-2436. https://doi.org/10.1002/wrcr.20174

46. Wickham H (2016). ggplot2: elegant graphics for data analysis. Springer-Verlag New York. ISBN 978-3-319-24277-4. https:// ggplot2.tidyverse.org

47. Zedler PH (2003) Vernal pools and the concept of "isolated wetlands." Wetlands 23:597-607. https://doi.org/10.1672/02775212(2003)023[0597:vpatco]2.0.co;2

48. Zedler PH (1987) The ecology of southern California vernal pools: a community profile. Fish and Wildlife Service, U.S. Dept. of the Interior

49. Zhang K, Shi Y, Cui X, et al (2019) Salinity is a key determinant for soil microbial communities in a desert ecosystem. mSystems. doi: https://doi.org/10.1128/msystems.00225-18

50. Zhou J, Ning D (2017) Stochastic community assembly: does it matter in microbial ecology? Microbiol Mol Biol Rev. https://doi. org/10.1128/mmbr.00002-17

51. Zwart G, Hannen EJV, Agterveld MPK-V et al (2003) Rapid screening for freshwater bacterial groups by using reverse line blot hybridization. Appl Environ Microbiol 69:5875-5883. https:// doi.org/10.1128/aem.69.10.5875-5883.2003 